\title{
Influence of Sandwich-Type Constrained Layer Damper Design Parameters on Damping Strength
}

\author{
Inaki Merideno, ${ }^{1}$ Javier Nieto, ${ }^{2}$ Nere Gil-Negrete, ${ }^{3}{ }^{J}$ osé Germán Giménez Ortiz, ${ }^{1}$ \\ Aitor Landaberea, ${ }^{4}$ and Jon Iartza ${ }^{4}$ \\ ${ }^{1}$ Tecnun-University of Navarra, Manuel Lardizabal 13, 20018 San Sebastián, Spain \\ ${ }^{2}$ CEIT, Manuel Lardizabal 15, 20018 San Sebastián, Spain \\ ${ }^{3}$ CEIT and Tecnun-University of Navarra, Manuel Lardizabal 15, 20018 San Sebastián, Spain \\ ${ }^{4}$ CAF, Jose Miguel Iturrioz 26, 20200 Beasain, Spain
}

Correspondence should be addressed to Inaki Merideno; imerideno@tecnun.es

Received 21 August 2015; Accepted 2 February 2016

Academic Editor: Emiliano Mucchi

Copyright (C) 2016 Inaki Merideno et al. This is an open access article distributed under the Creative Commons Attribution License, which permits unrestricted use, distribution, and reproduction in any medium, provided the original work is properly cited.

\begin{abstract}
This paper presents a theoretical study of the parameters that influence sandwich-type constrained layer damper design. Although there are different ways to reduce the noise generated by a railway wheel, most devices are based on the mechanism of increasing wheel damping. Sandwich-type constrained layer dampers can be designed so their resonance frequencies coincide with the wheel's resonant vibration frequencies, and thus the damping effect can be concentrated within the frequency ranges of interest. However, the influence of design parameters has not yet been studied. Based on a number of numerical simulations, this paper provides recommendations for the design stages of sandwich-type constrained layer dampers.
\end{abstract}

\section{Introduction}

The environmental requirements for railway operation are becoming more and more demanding. In particular, railway noise has to be taken into account as freight traffic increases and urban trams, metro lines, and high speed lines spread all over the world. Noise reduction at the source is more attractive than the use of noise barriers, but this requires a thorough understanding of the noise source mechanisms as well as methodologies to evaluate the effectiveness of proposed solutions [1].

Different sources may contribute to the total noise level, but wheel/rail noise is the most important noise source at middle speed ranges $(50-250 \mathrm{~km} / \mathrm{h}$ ), where the vast majority of trains run [2]. At low frequencies the noise is mainly radiated by the sleeper and the rail, whereas at high frequencies (around $1500 \mathrm{~Hz}$ ), the wheel is the dominant noise source [3]. Thus, the wheel is one of the most critical components of railway noise emission, and the study of its vibroacoustics has attracted the attention of many researchers due to its significant complexity [4].
The main wheel/rail noise sources are rolling noise, impact noise, or squeal noise, this last one being the most difficult to mitigate. Wheel squeal is considered to be caused by an instability in wheel vibrations [4-6], so sufficient positive damping, which is only a small fraction of critical damping, can actually stabilize these wheel vibrations and reduce squeal.

Different ways of increasing wheel damping have been reported in the literature, the most important ones being resilient wheels [7-10], ring dampers [7, 11-14], CAF dampers $[15,16]$, and constrained layer dampers (CLD) [17-20], either as a treatment applied on the wheel web $[1,7,9,21-25]$ or as tuned absorbers [1, 7, 26-28].

This paper is focused on sandwich-type CLD tuned absorbers, which are frequently employed in metro wheel cases. Sandwich-type CLDs are devices that combine metallic sheets with viscoelastic layers, and they increase the damping of the railway wheel modes. The damping is due to the energy dissipation that occurs through the deformation of the viscoelastic material. 
A sandwich-type CLD can be designed to reduce both squeal and rolling noise, depending on the treatment configuration. One advantage of the sandwich-type CLD is that it ages well, and it can be removed from a worn wheel and installed on a new one [7]. It can be designed so its resonance frequencies will coincide with wheel resonant vibration frequencies [7, 29], and thus its damping effect can be concentrated within the frequency ranges of interest. The possibilities are endless, and the same problem can often be solved by a number of different solutions.

Merideno et al. [30, 31] highlighted the need to develop a specific model that calculates the damping added by sandwich-type CLD to the railway wheel, in order to avoid experimental measurements. They presented a procedure that could be employed in design stages where the damping device is not available. The calculated damping can then be used to simulate the noise generated by a railway wheel $[32,33]$.

This paper makes use of the damping prediction model developed by Merideno et al. [30] to analyse several design parameters of the sandwich-type CLD solution and study their influence on the resulting total damping of the wheeldamper system. The effective noise reduction is not investigated in this paper, since the influence of wheel/rail contact on the radiated noise is out of the scope of this paper. The objective is that the results presented in this paper will be able to serve as a guideline for sandwich-type CLD designs, even for structures other than the railway wheel.

\section{Objective Function and Design Parameters}

According to Merideno et al. [30], the final modal damping ratio (the damping ratio of the wheel with the damping solution) can be calculated as

$$
\xi_{\text {equiv }_{r}}=\xi_{r}+\sum_{t=1}^{D} \frac{\left\{\phi_{r t}\right\}^{2} \sum_{s=1}^{M}\left\{Y_{s}\right\}}{2 m_{r} w_{r}^{2}},
$$

(see [30]) where $D$ represents the total number of sandwichtype devices attached to the railway wheel and $\sum_{s=1}^{M}\left\{\Upsilon_{s}\right\}$ refers to the sum of the base reaction forces (the imaginary part) appearing in each damper. The theoretical development of this equation can be found in the literature, and so it is not repeated here.

In this equation, the terms $\xi_{r}, \phi_{r t}$, and $m_{r}$ are specific to the undamped wheel, so if we only aim to study the damping strength of a given sandwich-type CLD in the frequency domain and independently of the railway wheel, these parameters should not be considered. The term $\sum_{s=1}^{M}\left\{\Upsilon_{s}\right\}$ refers to all the reaction forces in the damper base nodes, making it directly related to the damping strength that a particular sandwich-type CLD design would have, independent of the railway wheel. The term $w_{r}$ refers to the wheel's natural frequencies, but when a given sandwich-type CLD is attached to a given railway wheel, $w_{r}$ corresponds to the vibration frequency at which the damper is excited. Therefore, instead of understanding this frequency term as the natural frequency of the railway wheel, it must be understood as the vibration frequency at which the damper

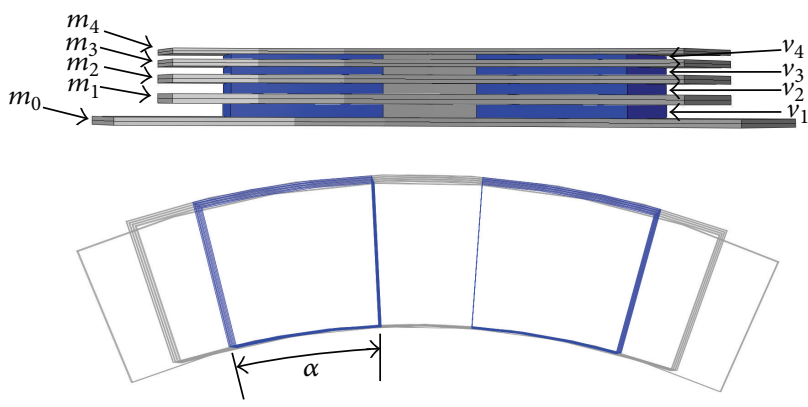

FIGURE 1: Designing parameters of a sandwich-type CLD.

is excited. However, when comparing different sandwichtype CLD designs that concentrate their damping strength on different frequency ranges, the reaction forces are normally higher for higher vibrational frequencies. Because of this, we define the concept of damping potential as normalizing in terms of frequency the damping strength of a damping solution:

$$
\nabla \xi(\omega)=\frac{\sum_{s=1}^{M} \Upsilon_{s}(\omega)}{\omega^{2}},
$$

where $M$ is related to the total amount of damper base nodes. This damping potential frequency-dependent value is the objective function in our study, since it defines the potentiality of a sandwich-type CLD to add damping to a given structure in the frequency domain. The frequency at which the sandwich-type CLD has a high damping potential value must then coincide with the frequency at which the designer wants to add damping in the structure to ensure the effectiveness of the sandwich-type CLD.

Now that the objective function has been defined, the design parameters under study will be described. The nomenclature that will be used hereafter for the geometric design parameters of a sandwich-type CLD is illustrated in Figure 1, which shows a scheme of a four-layer sandwich-type CLD, where $m_{i}$ refers to the thickness of the $i$ th metallic sheet (where 0 corresponds to the base sheet), $v_{i}$ refers to the thickness of the $i$ th viscoelastic layer, and $\alpha$ refers to the angle of the viscoelastic layers. This is a typical design employed in railway wheels for squeal noise. As it is usually an arc-type design, angle $\alpha$ is preferable to referring to the length of the viscoelastic layer.

The material of the metallic sheets remains the same (steel in this case) and its influence was not studied because commercial sandwich-type CLDs are made of steel. In addition to this, the thicknesses of the metallic sheets always have values that are whole or half numbers since these are the common commercial thicknesses. The maximum thickness of both the metallic sheets and viscoelastic layers is limited due to the space restrictions of railway wheels. In other applications, bigger sandwich-type CLDs could be appropriate.

In this paper, the influence that viscoelastic properties (Section 3) and the $m_{i}, v_{i}$, and $\alpha$ parameters (Section 4) of sandwich-type CLDs have on the damping potential will be studied, and different sandwich-type CLD design simulations will be carried out to examine the effect of varying different 
TABLE 1: Material properties of Mat1, Mat2, and reference material.

\begin{tabular}{lccc}
\hline $\begin{array}{l}\text { Average } \\
\text { properties }\end{array}$ & Mat1 & Mat2 & Reference material \\
\hline $\begin{array}{l}\text { Static shear } \\
\text { modulus }\end{array}$ & $5.84 \cdot 10^{4} \mathrm{~Pa}$ & $3.37 \cdot 10^{5} \mathrm{~Pa}$ & $1.4 \cdot 10^{5} \mathrm{~Pa}$ \\
$\begin{array}{l}\text { Dynamic shear } \\
\text { modulus }\end{array}$ & $1 \cdot 10^{5} \mathrm{~Pa}$ & $2.1 \cdot 10^{6} \mathrm{~Pa}$ & $4.6 \cdot 10^{5} \mathrm{~Pa}$ \\
\begin{tabular}{l} 
Loss angle \\
\hline
\end{tabular} & $15^{\circ}$ & $33^{\circ}$ & $22^{\circ}$ \\
\hline
\end{tabular}

design parameters and the assembly (Section 5). Finally, general recommendations for the design stages of sandwichtype CLDs will be presented (Section 6).

\section{Influence of Viscoelastic Properties}

The two predominant properties of a viscoelastic material are its stiffness and loss factor (internal damping). Generally, a viscoelastic material with a high damping factor tends to be very stiff, whereas a material with a low damping factor is usually related to low stiffness. Thus, a trade-off between these two properties has to be found when designing a sandwichtype CLD.

If the viscoelastic material of a sandwich-type CLD is too stiff, little shear deformation occurs, even though the damping factor is very high, which results in low energy dissipation. The structure and the constraining sheet become rigidly coupled and the material does not deform. On the other hand, if the viscoelastic material is too flexible, both the structure and the constraining sheet nearly become uncoupled. The material undergoes large deformations, but it adds little damping since it offers no resistance, resulting in minimal energy dissipation.

When applying a cyclic load to a viscoelastic material, a phase difference between stress and strain known as hysteresis occurs, leading to energy dissipation that results in damping [34]. This hysteresis energy loss can be defined by the loss angle, which relates the in-phase (storage) shear modulus and the out-of-phase (loss) shear modulus [35, 36].

In order to determine realistic variabilities in the loss angle and stiffness of viscoelastic materials and study their influence on the damping strength of the sandwich-type CLD under study, two materials that present extreme stiffness and loss angle properties were selected. The first material, Mat1, presents low stiffness and thus a low loss factor; the second material, Mat2, presents high stiffness and therefore a high loss factor.

By calculating the geometric mean of these materials' properties, a reference material was defined over the frequency range under study $(100-5000 \mathrm{~Hz})$. Table 1 presents the properties of all three materials.

3.1. Loss Angle of Viscoelastic Material. In a sandwich-type CLD damping is due to the energy dissipation that occurs through the shear deformation of the viscoelastic material. Since the loss angle is a measure of the material's internal damping behaviour, polymers are normally chosen for these types of dampers because of their high loss angle relative to

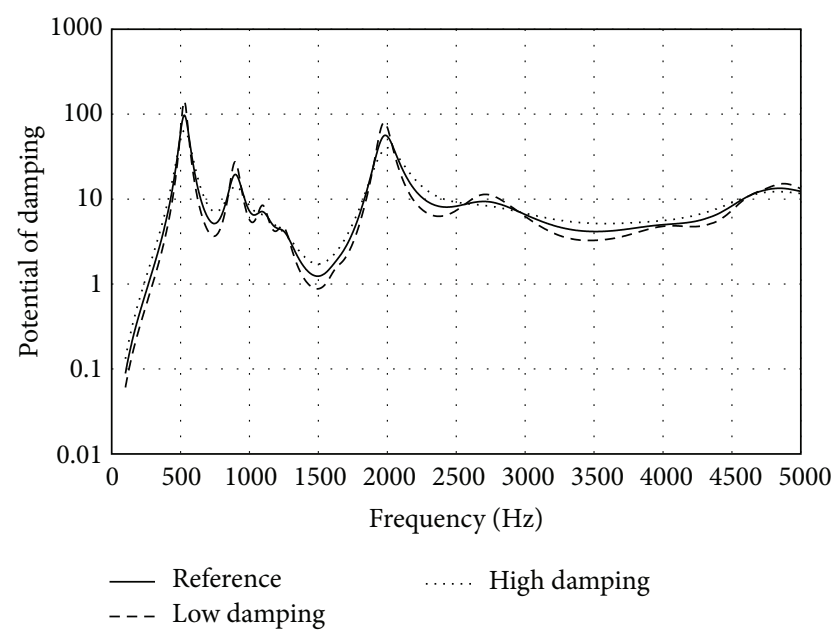

FIGURE 2: Damping potential for viscoelastic materials with different loss angles.

other viscoelastic materials. However, it is not clear whether having the highest possible loss angle value is beneficial or not.

In this section, the influence of the viscoelastic loss angle on the damping potential is analysed. First, a reference fourlayer sandwich-type CLD design was modelled with the reference viscoelastic material (see Table 2), whose dynamic properties were kept constant over the whole frequency range under study. The sandwich-type CLD modelling methodology described by Merideno et al. [29, 30] was used.

Then, two variations of the sandwich-type CLD design were built by setting the loss angle of the viscoelastic material to the extreme cases considered in Table $1,15^{\circ}$ (low damping model) and $33^{\circ}$ (high damping model), leaving the rest of the parameters unchanged (see Table 3). In each damper model, a unity displacement was applied laterally to the damper base and reaction forces were calculated at the base nodes. These reaction forces were divided by the square of their corresponding frequency and the damping potential was calculated in the $100-5000 \mathrm{~Hz}$ frequency range.

Figure 2 presents the calculated damping potential in the frequency range of interest for the reference, low damping and high damping sandwich-type CLD models built. As shown, the natural frequencies of these dampers were insignificantly affected by the loss angle values used in each design. The peak amplitudes of the low damping model were twice the values of the high damping model, whereas the valley amplitudes of the high damping model were twice the values of the low damping model. As a consequence, the peaks and valleys of the low damping model were more pronounced.

Thus, a sandwich-type CLD that has viscoelastic material with a low loss angle must be more accurately designed in order to concentrate its strength to a given frequency than a damper made of a viscoelastic material that has a high loss angle. Special attention should be paid to the variation of the natural frequencies of a railway wheel damped with a sandwich-type CLD solution with pronounced peaks, since it might be detuned. If the wheel's natural frequency coincided with a valley of the damping potential curve 
TABLE 2: Geometric parameters of the reference four-layer damper design.

\begin{tabular}{lcc}
\hline Metallic sheets & Viscoelastic layers & Viscoelastic properties \\
\hline$m_{0}=3 \mathrm{~mm}$ & $v_{1}=3.5 \mathrm{~mm}$ & Density $=1000 \mathrm{~kg} / \mathrm{m}^{3}$ \\
$m_{1}=3.5 \mathrm{~mm}$ & $v_{2}=3.5 \mathrm{~mm}$ & Static shear modulus $=1.4 \cdot 10^{5} \mathrm{~Pa}$ \\
$m_{2}=3 \mathrm{~mm}$ & $v_{3}=3.5 \mathrm{~mm}$ & Loss angle $=22^{\circ}$ \\
$m_{3}=2.5 \mathrm{~mm}$ & $v_{4}=3.5 \mathrm{~mm}$ & Poisson modulus $=0.499$ \\
$m_{4}=2 \mathrm{~mm}$ & $\alpha=10.5^{\circ}$ & Dynamic shear modulus $=4.6 \cdot 10^{5} \mathrm{~Pa}$ \\
\hline
\end{tabular}

TABLE 3: Viscoelastic material properties of the reference, low damping, and high damping models.

\begin{tabular}{lccc}
\hline $\begin{array}{l}\text { Average } \\
\text { properties }\end{array}$ & Reference & Low damping & High damping \\
\hline $\begin{array}{l}\text { Static shear } \\
\text { modulus }\end{array}$ & $1.4 \cdot 10^{5} \mathrm{~Pa}$ & $1.4 \cdot 10^{5} \mathrm{~Pa}$ & $1.4 \cdot 10^{5} \mathrm{~Pa}$ \\
$\begin{array}{l}\text { Dynamic shear } \\
\text { modulus }\end{array}$ & $4.6 \cdot 10^{5} \mathrm{~Pa}$ & $4.6 \cdot 10^{5} \mathrm{~Pa}$ & $4.6 \cdot 10^{5} \mathrm{~Pa}$ \\
Loss angle & $22^{\circ}$ & $15^{\circ}$ & $33^{\circ}$ \\
\hline
\end{tabular}

TABLE 4: Viscoelastic material properties of the reference and soft and stiff material models.

\begin{tabular}{lccc}
\hline $\begin{array}{l}\text { Average } \\
\text { properties }\end{array}$ & Reference & Soft material & Stiff material \\
\hline $\begin{array}{l}\text { Static shear } \\
\text { modulus }\end{array}$ & $1.4 \cdot 10^{5} \mathrm{~Pa}$ & $5.84 \cdot 10^{4} \mathrm{~Pa}$ & $3.37 \cdot 10^{5} \mathrm{~Pa}$ \\
$\begin{array}{l}\text { Dynamic shear } \\
\text { modulus }\end{array}$ & $4.6 \cdot 10^{5} \mathrm{~Pa}$ & $1 \cdot 10^{5} \mathrm{~Pa}$ & $2.1 \cdot 10^{6} \mathrm{~Pa}$ \\
Loss angle & $22^{\circ}$ & $22^{\circ}$ & $22^{\circ}$ \\
\hline
\end{tabular}

(an example of wheel's natural frequencies can be found in [33]), the sandwich-type CLD would have a null effect and the wheel would behave like an undamped wheel. We call this phenomenon the valley effect.

In sum, a trade-off has to be found when choosing a viscoelastic material for a sandwich-type CLD design: using a viscoelastic material with a low loss angle will present higher damping strength at a particular frequency, but a viscoelastic material with a high loss angle will be effective even when the wheel wears down and its natural frequencies vary.

3.2. Stiffness of Viscoelastic Material. In an analogous manner, the influence that stiffness of the viscoelastic material has on the damping potential, as measured by the static and dynamic shear modulus, is studied using the same reference four-layer sandwich-type CLD design and viscoelastic material (Table 2) and building two new models that represent the extreme stiffness conditions identified in Table 1.

The viscoelastic materials used are in Table 4 and the damping potential curves calculated in the $100-5000 \mathrm{~Hz}$ frequency range are shown in Figure 3.

The sandwich-type CLD design with the soft material had its peaks (at least the first three peaks) at lower frequencies than the other designs. Therefore, estimating the optimal stiffness of the viscoelastic material is tied to the optimal location of the damper's natural frequencies, mainly to

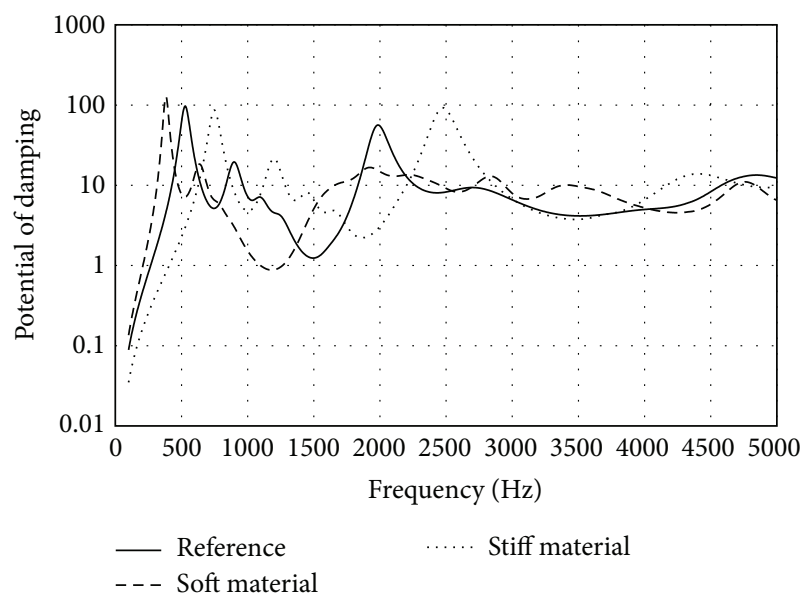

FIGURE 3: Damping potential for viscoelastic materials with different stiffness values.

the first natural frequency since it determines the initial frequency at which a sandwich-type CLD design starts to add damping to a given railway wheel.

In terms of the damping potential peak amplitudes, at the dampers' first natural frequencies, even though peak differences between the three damping potential curves were not significant, the peak amplitude when the viscoelastic material was soft was higher than for the other models. On the contrary, at the dampers' second natural frequencies, the peak amplitude when the viscoelastic material was stiff was slightly higher than for the other models. At frequencies above $1500 \mathrm{~Hz}$, it is not possible to reach any conclusions.

\section{Influence of Geometric Parameters}

A sandwich-type CLD can be designed in order to concentrate its damping strength in a given frequency range by properly defining its geometric parameters: thickness and angle of each viscoelastic layer and thickness of each metallic sheet.

In what follows, the effect of varying the thickness and angle of viscoelastic layers is presented. Conclusions about the influence of the thickness of metallic sheets are also presented.

4.1. Thickness of the Viscoelastic Layer. This section studies the effect that the thickness of the viscoelastic layers has on the damping potential through studying a monolayer damper. 
TABLE 5: Geometric parameters of the reference monolayer damper design.

\begin{tabular}{lcc}
\hline Metallic sheets & Viscoelastic layer & Viscoelastic properties \\
\hline & & Density $=1000 \mathrm{~kg} / \mathrm{m}^{3}$ \\
$m_{0}=3 \mathrm{~mm}$ & $v_{1}=1.5-6.5 \mathrm{~mm}$ & Static shear modulus $=1.4 \cdot 10^{5} \mathrm{~Pa}$ \\
$m_{1}=3.5 \mathrm{~mm}$ & $\alpha=10.5^{\circ}$ & Loss angle $=22^{\circ}$ \\
& & Poisson modulus $=0.499$ \\
& & Dynamic shear modulus $=4.6 \cdot 10^{5}$ Pa \\
\hline
\end{tabular}

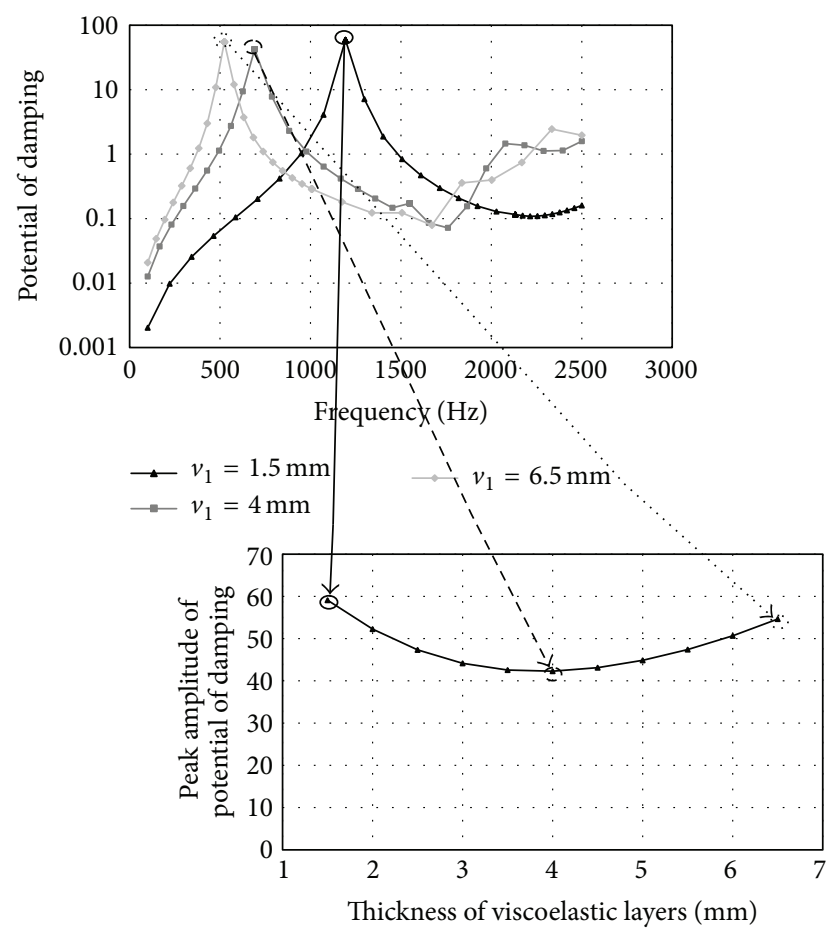

FIgURE 4: Damping potential of a monolayer damper for different thickness of the viscoelastic layer.

First, a monolayer sandwich-type CLD model denoted M01 was built with the reference viscoelastic material and with the geometry detailed in Table 5 . The thickness of the viscoelastic layer was varied from $1.5 \mathrm{~mm}$ to $6.5 \mathrm{~mm}$ with a step of $0.5 \mathrm{~mm}$, and in each simulation the damping potential was calculated. From each damping potential curve, the peak amplitudes of the first mode were extracted and plotted together (Figure 4) in order to study the influence that varying the thickness of the viscoelastic layers had on the damping potential.

Figure 4 shows that the highest damping potential peak amplitudes were calculated for the smallest and the biggest thickness values, that is, when the thickness was set to $1.5 \mathrm{~mm}$ and $6.5 \mathrm{~mm}$. Intermediate thickness values led to lower damping potential peak amplitudes.

Then, the other two monolayer sandwich-type CLDs, M02 and M03, were modelled in the same way as M01; only in these two models was the thickness of the upper metallic sheet set to $5 \mathrm{~mm}$ and $7 \mathrm{~mm}$, respectively. Table 6 shows the geometric parameters for the M01, M02, and M03 sandwich-type CLD designs. Once again, the thickness of the viscoelastic layer in each design was varied from $1.5 \mathrm{~mm}$ to $6.5 \mathrm{~mm}$ with a step of $0.5 \mathrm{~mm}$.

Figure 5(a) presents the first peak amplitude of the damping potential curve for each design versus the thickness of the viscoelastic layer. The same trend emerged when varying the thickness of the viscoelastic layers in the three sandwich-type CLD designs: the highest damping potential peak amplitudes were calculated for the lowest and the highest thickness values, and for the intermediate thickness value the minimal damping potential peak amplitude was obtained.

Figure 5(b) presents the influence of the thickness of the viscoelastic layer on the damper's first natural frequency. As shown, the first natural frequency decreased continuously when the viscoelastic layer thickness increased.

Figure 5(c) presents the influence of the thickness of the viscoelastic layer on the sum of all of the reaction forces (the imaginary part) on the base of sandwich-type CLDs. As shown, the curves followed a concave shape: for the highest and the lowest viscoelastic layer thickness values the reaction forces increased, and this behaviour was sharper for the lowest viscoelastic layer thickness.

An increase in the viscoelastic layer thickness results in an enlargement of the energy dissipation, since the amount of viscoelastic material is increased. This is the reason for the positive slope of the curve in Figure 5(a) when higher viscoelastic thickness values are used. When the viscoelastic layer thickness is small, even though the energy dissipation through the viscoelastic material is low, the movement of the top metallic sheet is fully transmitted to the base sheet, which leads to a significant increase in the resulting reaction forces. This fact explains the negative slope of the curve in Figure 5(a) for the lowest thickness values. Nevertheless, the highest damping potential peak amplitudes were attained for the highest thickness values of the viscoelastic layer.

In analysing the peak amplitude of damping potential for a specific thickness of the viscoelastic layer of each damper design in Figure 5(a), the highest value was obtained for the M03 design, which had the highest upper metallic sheet thickness. The highest damping potential peak amplitude was attained with the M03 sandwich-type CLD design, which consists of a $6.5 \mathrm{~mm}$ thick viscoelastic layer and a $7 \mathrm{~mm}$ thick upper metallic sheet, that is, the damper design that had the highest total thickness.

In conclusion, the increase in thickness in the viscoelastic layer and in the upper metallic sheet results in higher energy dissipation through the viscoelastic material, and therefore there is an increase in the damping potential. Since geometric 
TABLE 6: Geometric parameters of the three monolayer damper designs.

\begin{tabular}{lccccc}
\hline & M01 & \multicolumn{2}{c}{ M02 } & \multicolumn{2}{c}{ M03 } \\
Metallic sheets & Viscoelastic layers & Metallic sheets & Viscoelastic layers & Metallic sheets & Viscoelastic layers \\
\hline$m_{0}=3 \mathrm{~mm}$ & $v_{1}=1.5-6.5 \mathrm{~mm}$ & $m_{0}=3 \mathrm{~mm}$ & $v_{1}=1.5-6.5 \mathrm{~mm}$ & $m_{0}=3 \mathrm{~mm}$ & $v_{1}=1.5-6.5 \mathrm{~mm}$ \\
$m_{1}=3.5 \mathrm{~mm}$ & $\alpha=10.5^{\circ}$ & $m_{1}=5 \mathrm{~mm}$ & $\alpha=10.5^{\circ}$ & $m_{1}=7 \mathrm{~mm}$ & $\alpha=10.5^{\circ}$ \\
\hline
\end{tabular}

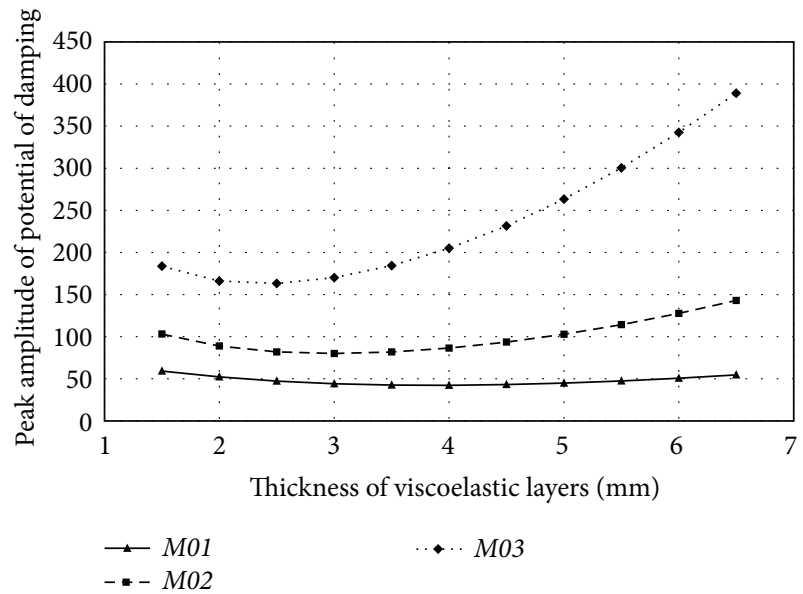

(a) Peak amplitude of damping potential for first mode

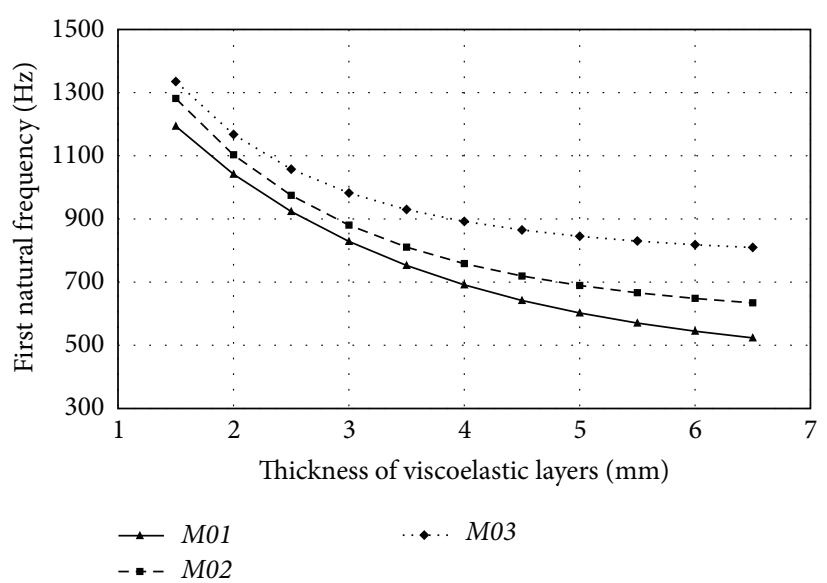

(b) Natural frequency of first mode

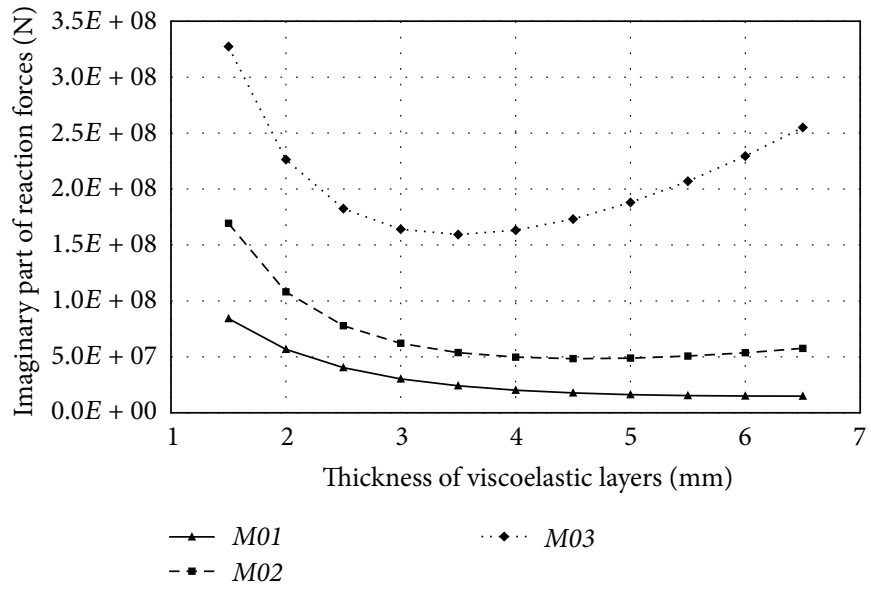

(c) Imaginary part of total reaction forces

FIgURE 5: Analysis of damping potential for different thicknesses of the viscoelastic layer.

and space limitations are common when designing sandwichtype CLD solutions for a given railway wheel, especially tram wheels, whether the upper metallic sheet thickness or the viscoelastic layer thickness is increased will depend on each design situation.

Lastly, an increase in the viscoelastic layer thickness leads to a decrease in the first natural frequency, whereas an increase in the upper metallic sheet thickness leads to an increase. The relative increase of each part will be determined by the optimal location of the first natural frequency.

4.2. Angle of the Viscoelastic Layer. In this section, the influence that varying the viscoelastic layer's $\alpha$-value has on the damping potential is analysed through a monolayer damper approach.
A monolayer sandwich-type CLD denoted L01 was built with the reference viscoelastic material and with the geometry detailed in Table 7. In this case, the thickness of the viscoelastic layer was fixed to $1.5 \mathrm{~mm}$ and its angle was varied from $2^{\circ}$ to $14.5^{\circ}$, which in the sandwich-type CLD design under study corresponded to the noncantilevered state of the upper metallic sheet. For angles smaller than this, the upper metallic sheet was partially cantilevered. For an $\alpha$-value of $10.5^{\circ}$, this damper design coincided with the previous M01 design.

As in the previous section, the $\alpha$-value was varied, and for each simulation, the peak amplitude of damping potential (Figure 6(a)) and the first natural frequency (Figure 6(b)) were plotted. In this sandwich-type CLD design, an increase in the $\alpha$-value corresponded to a decrease in the damping 
TABLE 7: Geometric parameters of the reference monolayer damper design.

\begin{tabular}{lcc}
\hline Metallic sheets & Viscoelastic layers & Viscoelastic properties \\
\hline & & Density $=1000 \mathrm{~kg} / \mathrm{m}^{3}$ \\
$m_{0}=3 \mathrm{~mm}$ & $v_{1}=1.5 \mathrm{~mm}$ & Static shear modulus $=1.4 \cdot 10^{5} \mathrm{~Pa}$ \\
$m_{1}=3.5 \mathrm{~mm}$ & $\alpha=2^{\circ}-14.5^{\circ}$ & Loss angle $=22^{\circ}$ \\
& & Poisson modulus $=0.499$ \\
& & Dynamic shear modulus $=4.6 \cdot 10^{5} \mathrm{~Pa}$ \\
\hline
\end{tabular}

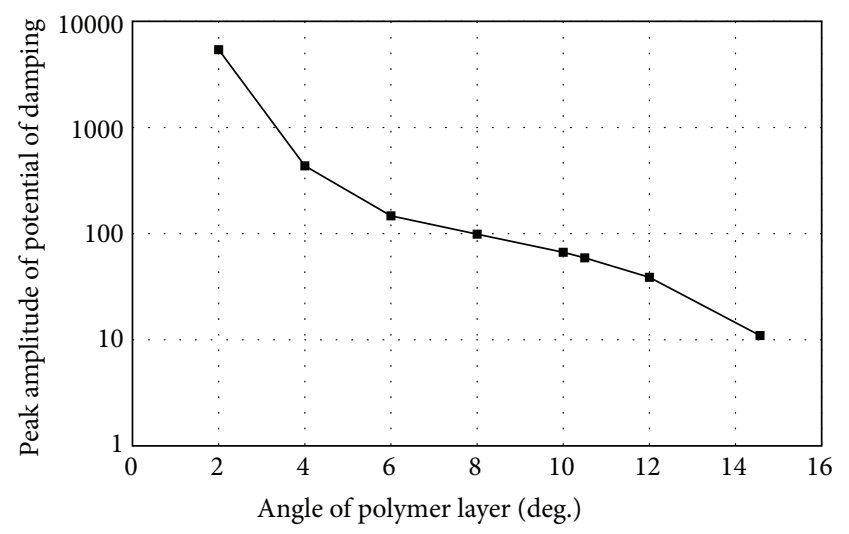

(a) Peak amplitude of damping potential

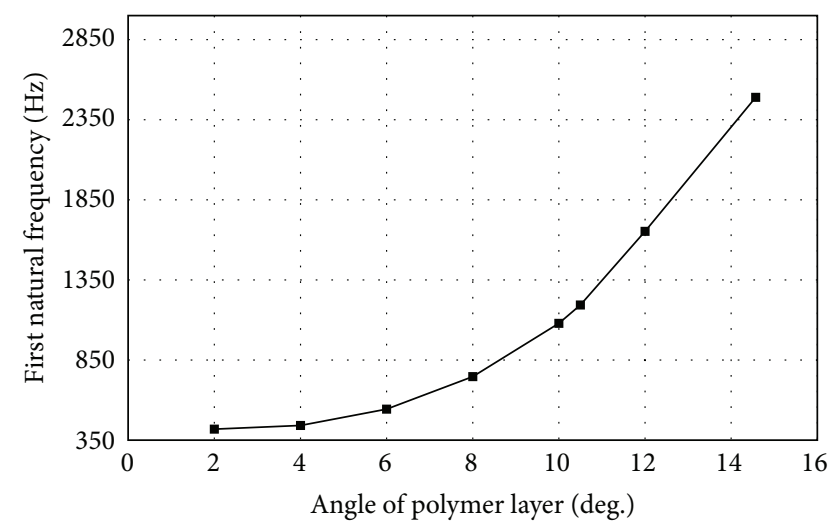

(b) First natural frequency

FIGURE 6: Influence of the angle of the viscoelastic layer on a monolayer damper.

potential peak amplitude and an increase in the first natural frequency.

Then, another two monolayer sandwich-type CLDs, L02 and L03, were modelled identically to L01 except for the thickness of the viscoelastic layer, which was set to $4 \mathrm{~mm}$ and $6.5 \mathrm{~mm}$, respectively. Table 8 gathers the geometric parameters of the sandwich-type CLD designs for L01, L02, and L03. Once again, the $\alpha$-value was varied from $2^{\circ}$ to $14.5^{\circ}$.

Figure 7 shows that the damping potential peak amplitude decreased when the $\alpha$-value increased, whereas the first natural frequency increased in each sandwich-type CLD design. In addition to this, the increase in the first natural frequency was more significant for the LO1 design, that is, for the sandwich-type CLD with the thinnest viscoelastic layer. Furthermore, for $\alpha$-values equal to $2^{\circ}$, the three sandwichtype CLD designs had approximately the same first natural frequency, which corresponded to the natural frequency of the metallic structure. As $\alpha$-values increased, the increase in the first natural frequency for the L03 damper design was lower than for the other designs. For the maximal $\alpha$-value, the first natural frequency of the L01 design is twice as high as the $L 03$ design. Therefore, the angle of the viscoelastic layer, the $\alpha$ value, can be used to adjust the damping strength to the frequency range of interest.

However, the $\alpha$-values adopted in commercial sandwichtype CLDs are usually high, which is not in line with what would be expected from the results in Figure 7(a). In order to clarify this disagreement, two variations of the L03 design were modelled: one with a viscoelastic layer of $3^{\circ}$ angle and the other with $11^{\circ}$ angle. Figure 8 shows that the peak of damping potential was higher for the $3^{\circ}$ angle than for the $11^{\circ}$-angle, meaning that a higher damping strength would be attained with lower $\alpha$-values. However, Figure 8 shows that the peak of damping potential was more pronounced for the $3^{\circ}$ angle than for the $11^{\circ}$ angle. Therefore, a sandwichtype CLD with a viscoelastic layer with a low $\alpha$-value has to concentrate its damping strength more precisely to a given wheel eigenfrequency. For this reason, a flatter damping potential curve is preferred so as to overcome a railway wheel's frequency variations due to the wheel wearing down as well as the valley effect.

\section{Damper Design}

The influence of several design parameters of sandwich-type CLDs has been studied in the previous sections. In this section, the influence of the relative thicknesses of the different parts of a multilayer sandwich-type CLD and the order in which they are assembled is studied. For this purpose, twolayer sandwich-type CLDs are analysed in Sections 5.1, 5.2, and 5.3, and four-layer sandwich-type CLDs are analysed in Section 5.4.

5.1. Two-Layer Sandwich-Type CLD: Influence of Metallic Sheets. The influence that the metallic sheets' thickness has on two-layer sandwich-type CLDs of identical viscoelastic layers $\left(v_{1}=v_{2}\right.$ in Figure 9) was studied by modelling and building different metallic sheets and viscoelastic layer configurations using the reference viscoelastic material detailed in Table 1. 
TABLE 8: Geometric parameters of the three mono-layer damper designs.

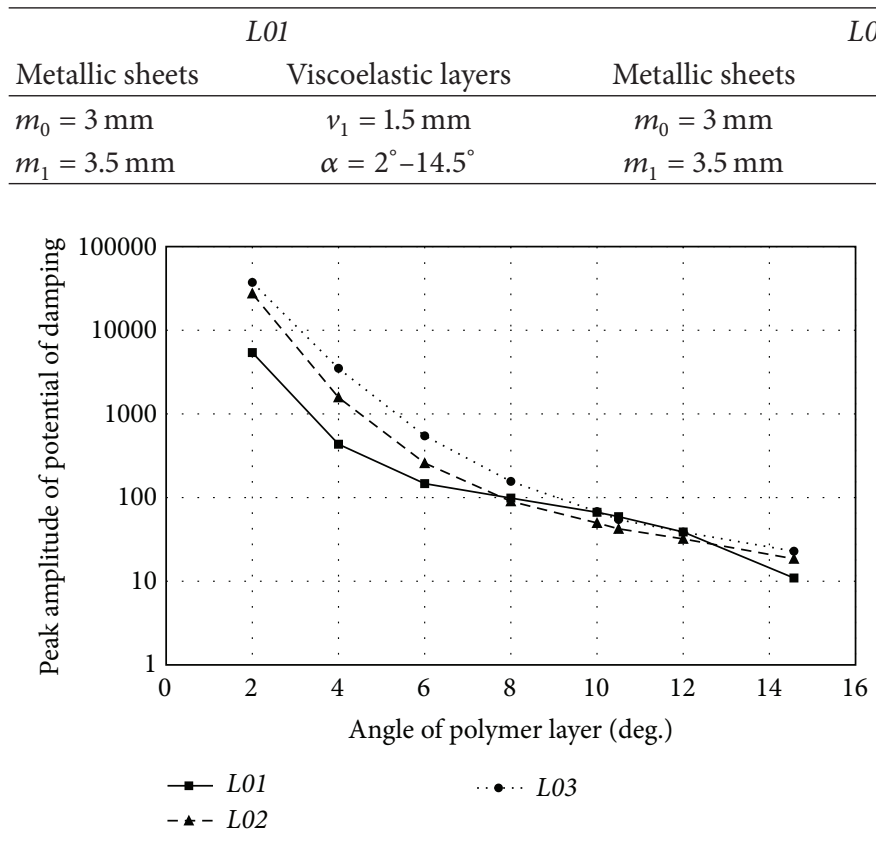

(a) Peak amplitude of damping potential

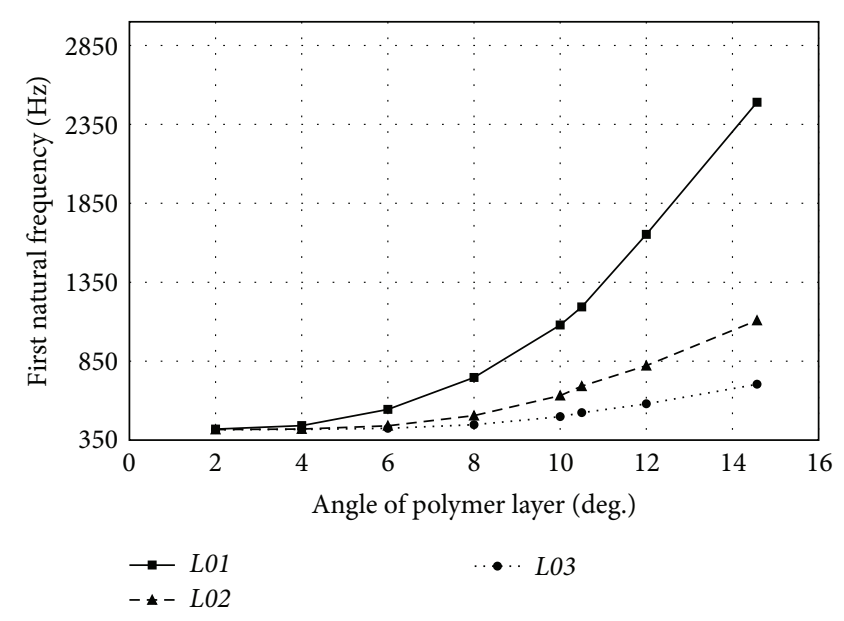

(b) First natural frequency

FIGURE 7: Influence of the angle of the viscoelastic layer on the L01, L02, and L03 monolayer damper designs.

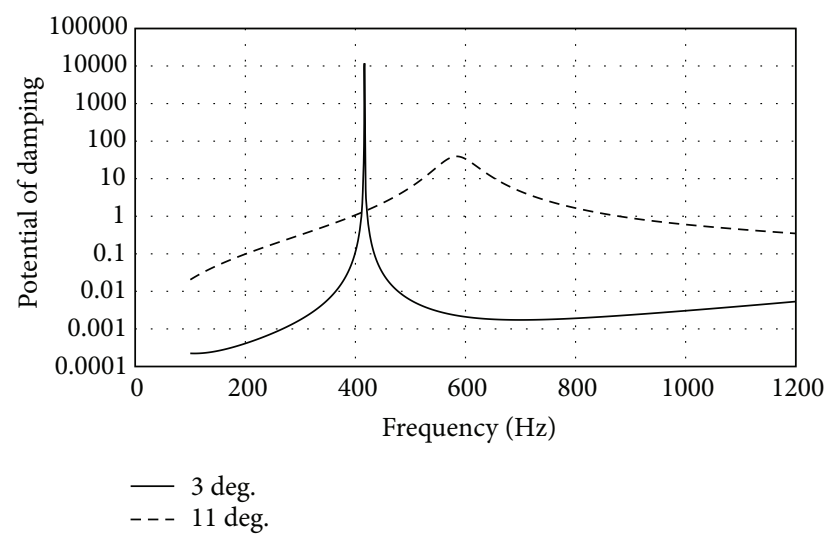

FIGURE 8: Damping potential for two particular sandwich-type CLD designs.

Table 9 gathers the two-layer sandwich-type CLD designs that were modelled and simulated and the results. The thicknesses of the middle and upper metallic sheets were varied (the thickness of the base metallic sheet was fixed at $m_{0}=3 \mathrm{~mm}$ ) and the viscoelastic layer thickness was adjusted in order to always set the first natural frequency to approximately $400 \mathrm{~Hz}$.

The following design considerations can be highlighted:

(i) When the thickness of either of the two metallic sheets was increased, the first natural frequency of the damper increased. As a consequence, the viscoelastic layer thickness had to be increased to counteract this effect. This resulted in an increase in the damping potential, which can be seen, for example, by comparing designs 1 to 6 .

(ii) The damping potential was higher if the upper metallic sheet was thicker than the middle metallic sheet, in comparison with its analogue inverse design: designs 2 and 7, designs 3 and 8, designs 4 and 9, designs 5 and 10 , and designs 6 and 11 .

(iii) In order to keep the first natural frequency constant, the viscoelastic layer thickness had to be increased more when the thickness of the upper metallic sheet was increased than when the thickness of the middle metallic sheet was increased (see the abovementioned inverse designs).

(iv) If the thickness of the upper metallic sheet was much greater than the thickness of the middle metallic sheet, the first modal shape transformed from a mode in which both metallic sheets deformed together (see Figure $10(\mathrm{a})$ ) to a mode in which only the middle metallic sheet deformed (see Figure 10(b)). When this happened, the damping potential dropped dramatically, as seen in designs 11 and 12 .

5.2. Two-Layer Sandwich-Type CLD: Influence of Viscoelastic Layers. Once the influence of metallic sheet' thickness had been studied, the influence of the relative thicknesses of the viscoelastic layers was analysed through two-layer sandwichtype CLDs composed of viscoelastic layers of different thicknesses (see Figure 9). Table 10 presents the two-layer 


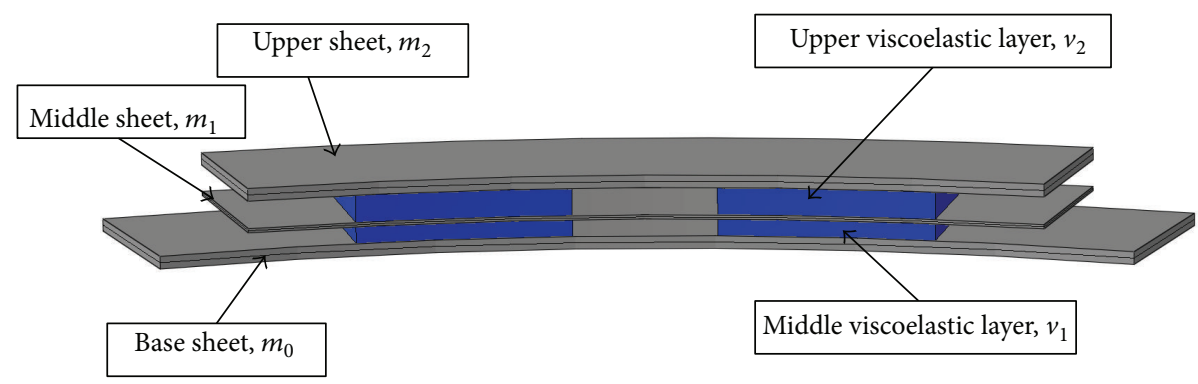

FiguRE 9: Scheme of a two-layer damper.

TABLE 9: Simulated two-layer sandwich-type CLD designing geometric parameters and simulation results. $m_{0}=3 \mathrm{~mm}$.

\begin{tabular}{|c|c|c|c|c|c|}
\hline \multirow{2}{*}{ Design } & \multicolumn{3}{|c|}{ Designing geometric parameters } & \multicolumn{2}{|c|}{ Results } \\
\hline & $m_{1}(\mathrm{~mm})$ & $m_{2}(\mathrm{~mm})$ & $v_{12}(\mathrm{~mm})$ & $w_{1}(\mathrm{~Hz})$ & Damp. pot. ${ }^{a}$ \\
\hline 1 & 1 & 1 & 4 & 400.12 & 18 \\
\hline 2 & 1.5 & 1 & 4.5 & 394.56 & 22 \\
\hline 3 & 2 & 1 & 4.5 & 405.41 & 24 \\
\hline 4 & 2.5 & 1 & 5 & 389.83 & 26 \\
\hline 5 & 3 & 1 & 5 & 396.62 & 28 \\
\hline 6 & 3.5 & 1 & 5 & 403.34 & 29 \\
\hline 7 & 1 & 1.5 & 5 & 391.42 & 27 \\
\hline 8 & 1 & 2 & 5 & 408.8 & 34 \\
\hline 9 & 1 & 2.5 & 5.5 & 401.15 & 44 \\
\hline 10 & 1 & 3 & 6 & 402.52 & 56 \\
\hline 11 & 1 & 3.5 & 6.5 & 407.79 & 55 \\
\hline 12 & 1 & 4 & 7 & 408.39 & 38 \\
\hline 13 & 1.5 & 1.5 & 5 & 401.18 & 32 \\
\hline 14 & 2 & 1.5 & 5 & 407.88 & 36 \\
\hline 15 & 2.5 & 1.5 & 5.5 & 390.49 & 42 \\
\hline 16 & 3 & 1.5 & 5.5 & 400.27 & 48 \\
\hline 17 & 3.5 & 1.5 & 6 & 392.66 & 54 \\
\hline 18 & 1.5 & 2 & 5.5 & 390.91 & 41 \\
\hline 19 & 1.5 & 2.5 & 5.5 & 407.778 & 55 \\
\hline 20 & 1.5 & 3 & 6.5 & 396.96 & 82 \\
\hline 21 & 1.5 & 3.5 & 7.5 & 402.07 & 97 \\
\hline 22 & 2 & 2 & 5.5 & 395.57 & 48 \\
\hline 23 & 2.5 & 2 & 5.5 & 402.45 & 55 \\
\hline 24 & 3 & 2 & 6 & 392.36 & 67 \\
\hline 25 & 3.5 & 2 & 6 & 405.29 & 73 \\
\hline 26 & 2 & 2.5 & 6 & 391.9 & 67 \\
\hline 27 & 2 & 3 & 6.5 & 401.74 & 98 \\
\hline 28 & 2 & 3.5 & 7.5 & 409.4 & 127 \\
\hline 29 & 2.5 & 2.5 & 6 & 398.81 & 78 \\
\hline 30 & 3 & 2.5 & 6 & 408.92 & 90 \\
\hline 31 & 3.5 & 2.5 & 6.5 & 406.84 & 105 \\
\hline 32 & 2.5 & 3 & 6.5 & 408.82 & 116 \\
\hline 33 & 2.5 & 3.5 & 8.5 & 403.29 & 172 \\
\hline 34 & 3 & 3 & 7.5 & 400.09 & 167 \\
\hline 35 & 3.5 & 3 & 8 & 405.96 & 193 \\
\hline 36 & 3 & 3.5 & 11 & 397.23 & 288 \\
\hline 37 & 3.5 & 3.5 & 15 & 406.28 & 782 \\
\hline
\end{tabular}

${ }^{a}$ Damp. pot. refers to the peak amplitude of the damping potential curve. 

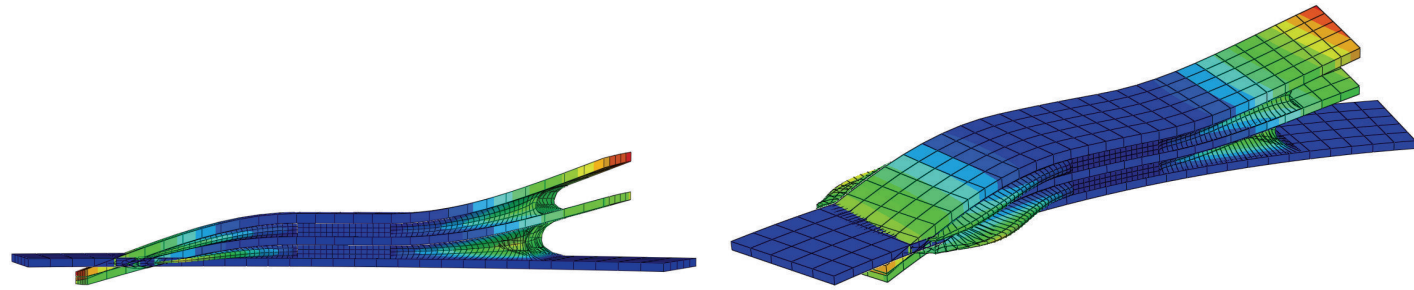

(a) Mode in which both metallic sheets deform together
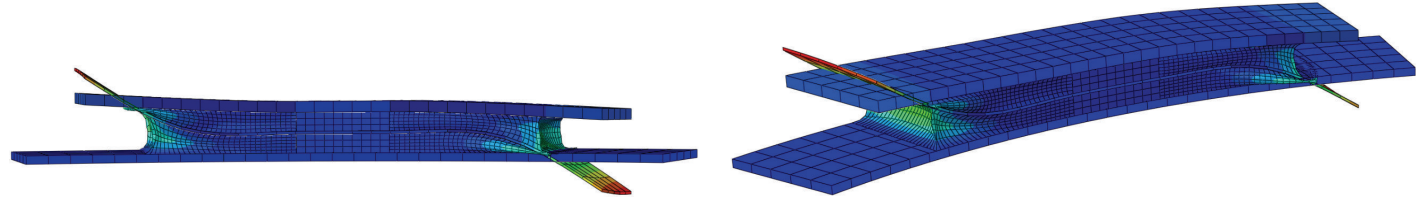

(b) Mode in which only the middle metallic sheet deforms

Figure 10: Different modal shapes.

sandwich-type CLD designs modelled and simulated. The thickness of the base metallic sheet was fixed at $m_{0}=3 \mathrm{~mm}$. Once again, these sandwich-type CLDs were designed to have their first natural frequency at around $400 \mathrm{~Hz}$ by adjusting the thickness of the upper viscoelastic layer. lighted:

The following designing considerations can be high-

(i) When the thickness of the upper metallic sheet was greater than the thickness of the middle metallic sheet, a higher damping potential was obtained if the thickness of the upper viscoelastic layer was also higher than the thickness of the middle viscoelastic layer. This tendency can be seen by comparing designs 7 and 10.

(ii) When the thickness of the middle metallic sheet was greater than the thickness of the upper metallic sheet, a higher damping potential was calculated if the thickness of the middle viscoelastic layer was also higher than the thickness of the upper viscoelastic layer. This tendency can be seen by comparing designs 1 and 2 .

(iii) A higher damping potential was achieved when the thicknesses of the upper metallic sheet and upper viscoelastic layer were greater than the thicknesses of the middle metallic sheet and the middle viscoelastic layer. In order to keep the first natural frequency constant, the total thickness had to be higher than the analogue inverse design, which can be observed by comparing designs 2 and 10.

In conclusion, if the total thickness of the sandwich-type CLD is not limited, in order to obtain the highest possible damping potential, the upper metallic sheet should be thicker than the middle metallic sheet and the upper viscoelastic layer should be thicker than the middle viscoelastic layer. The difference between both thicknesses should not exceed a given value, beyond which modal shapes change to a mode in which only the middle metallic sheet deforms and the damping potential drops.

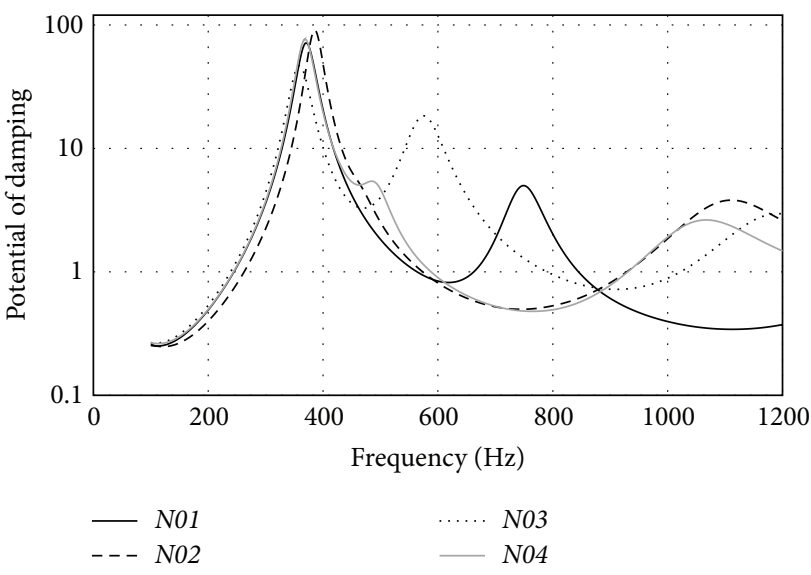

FIGURE 11: Damping potential for four damper designs.

5.3. Comparison of Representative Two-Layer Sandwich-Type CLD Designs. Four two-layer sandwich-type CLD models that represented the previous designs were analysed (see Table 11). These designs had metallic sheets that were $3 \mathrm{~mm}$ thick and a $1.5 \mathrm{~mm}$ thick, but the order in which the metallic sheets were assembled changed for each design. All the designs had a $3 \mathrm{~mm}$ thick base metallic sheet. Designs N01 and N02 consisted of viscoelastic layers of different thicknesses whereas designs N03 and N04 consisted of equal viscoelastic layers.

Figure 11 presents the damping potential in the frequency domain for each design. As shown, the highest peak amplitude for the first natural frequency corresponded to the N02 design, followed by N04, N01, and N03; the converse is true for the highest peak amplitude of the second natural frequency, which corresponded to the N03 design followed by N01, N04, and N02. It seemed that, for a given amount of viscoelastic material used in a two-layer sandwich-type CLD, the total damping potential was distributed around the damper modes, depending on the sandwich-type CLD design. 
TABLE 10: Simulated two-layer sandwich-type CLD designing geometric parameters and simulation results. $m_{0}=3 \mathrm{~mm}$.

\begin{tabular}{|c|c|c|c|c|c|c|}
\hline \multirow{2}{*}{ Design } & \multicolumn{4}{|c|}{ Designing geometric parameters } & \multicolumn{2}{|c|}{ Results } \\
\hline & $m_{1}(\mathrm{~mm})$ & $m_{2}(\mathrm{~mm})$ & $v_{1}(\mathrm{~mm})$ & $v_{2}(\mathrm{~mm})$ & $w_{1}(\mathrm{~Hz})$ & Pot. damp. \\
\hline 1 & 3 & 1.5 & 5.5 & 5.5 & 400.27 & 48 \\
\hline 2 & 3 & 1.5 & 7 & 2 & 398.8 & 68 \\
\hline 3 & 3 & 1.5 & 6 & 4.5 & 403.07 & 57 \\
\hline 4 & 3 & 1.5 & 5 & 6 & 400.58 & 40 \\
\hline 5 & 3 & 1.5 & 4 & 7 & 391.213 & 27 \\
\hline 6 & 3 & 1.5 & 3 & 7 & 402.2 & 21 \\
\hline 7 & 1.5 & 3 & 6.5 & 6.5 & 396.96 & 82 \\
\hline 8 & 1.5 & 3 & 7 & 2.5 & 397.5 & 70 \\
\hline 9 & 1.5 & 3 & 6 & 7 & 402.93 & 83 \\
\hline 10 & 1.5 & 3 & 5 & 9 & 402.46 & 88 \\
\hline 11 & 1.5 & 3 & 4 & 10 & 398.24 & 81 \\
\hline 12 & 1.5 & 3 & 3 & 10 & 401.48 & 72 \\
\hline 13 & 1.5 & 3 & 2 & 10.5 & 395.23 & 70 \\
\hline
\end{tabular}

TABLE 11: Simulated two-layer sandwich-type CLD designs.

\begin{tabular}{lccccc}
\hline Design & $m_{0}(\mathrm{~mm})$ & $m_{1}(\mathrm{~mm})$ & $m_{2}(\mathrm{~mm})$ & $v_{1}(\mathrm{~mm})$ & $v_{2}(\mathrm{~mm})$ \\
\hline N01 & 3 & 3 & 1.5 & 7 & 2 \\
N02 & 3 & 1.5 & 3 & 5 & 9 \\
N03 & 3 & 3 & 1.5 & 5.5 & 5.5 \\
N04 & 3 & 1.5 & 3 & 6.5 & 6.5 \\
\hline
\end{tabular}

5.4. Four-Layer Sandwich-Type CLD Approach. In order to prove the damping potential distribution hypothesis, fourlayer damper designs were modelled (see Table 12) using the viscoelastic reference material (Table 1).

The F01 design had four viscoelastic layers of the same thickness, and metallic sheets were assembled from the thickest to the thinnest, from bottom to top. The F02 design was identical to F01 except the metallic sheets were assembled in the inverse order. The F03 design had the same metallic structure as the F01 design, but the thicknesses of its viscoelastic layers were varied in consonance with the thicknesses of the metallic sheets. Finally, the F04 design had the same metallic structure as the F02 design, but its viscoelastic layers were also varied in consonance with the metallic sheets. All the designs had equal total thickness, since the total thicknesses of both the metallic sheets and the viscoelastic layers were kept constant. In this way, the same amount of viscoelastic material and the same metallic sheets were used for all sandwich-type CLD designs.

Figure 12 shows the damping potential in the frequency domain for the four-layer sandwich-type CLD designs. The area enclosed by each curve was calculated and it was approximately the same for the four configurations. This fact is in line with the damping potential distribution theory, which says that, for a given amount of metal and viscoelastic material, the total amount of damping potential is distributed around the damper natural modes depending on the chosen damper design.

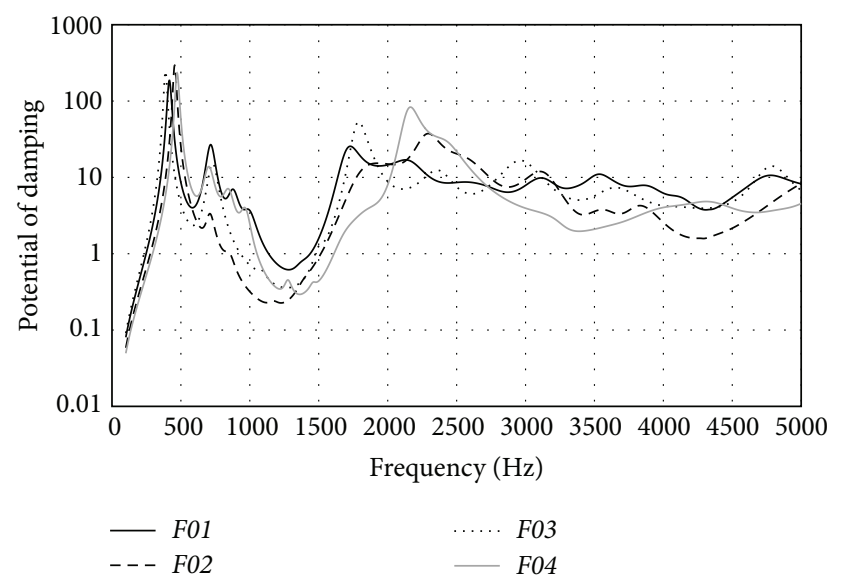

FIGURE 12: Damping potential for four multilayer damper designs.

\section{General Recommendations for Designing Sandwich-Type CLD Solutions}

The design of a given sandwich-type CLD solution depends on its aim. On one hand, a sandwich-type CLD solution designed for a broadband noise problem has to cover a wide frequency range with a relatively flat damping potential curve and avoid the valley effect as much as possible. This can be the case of undamped railway wheels, which normally present a huge number of vibrating modes in the 100$5000 \mathrm{~Hz}$ frequency range. In this case, multilayer designs and viscoelastic materials with relatively high loss angles are preferred, and different sandwich-type CLD designs can be combined in such a way that one design can counteract the potential valley effect of another, and vice versa.

For example, Figure 13 shows the damping potential of two different four-layer sandwich-type CLD designs. It can be seen that both curves are relatively flat (they have a high number of natural modes in the $100-5000 \mathrm{~Hz}$ frequency range) and that damper $B$ has its first peak just where damper 
TABLE 12: Simulated four-layer sandwich-type CLD designs.

\begin{tabular}{lcccccccc}
\hline Design & $m_{0}$ & $m_{1}$ & $m_{2}$ & $m_{3}$ & $m_{4}$ & $v_{1}$ & $v_{2}$ & $v_{3}$ \\
\hline F01 & 3 & 3.5 & 3 & 2.5 & 2 & 3.5 & 3.5 & 3.5 \\
F02 & 3 & 2 & 2.5 & 3 & 3.5 & 3.5 & 3.5 & 3.5 \\
F03 & 3 & 3.5 & 3 & 2.5 & 2 & 5 & 4 & 3.5 \\
F04 & 3 & 2 & 2.5 & 3 & 3.5 & 2 & 3 & 3 \\
\hline
\end{tabular}

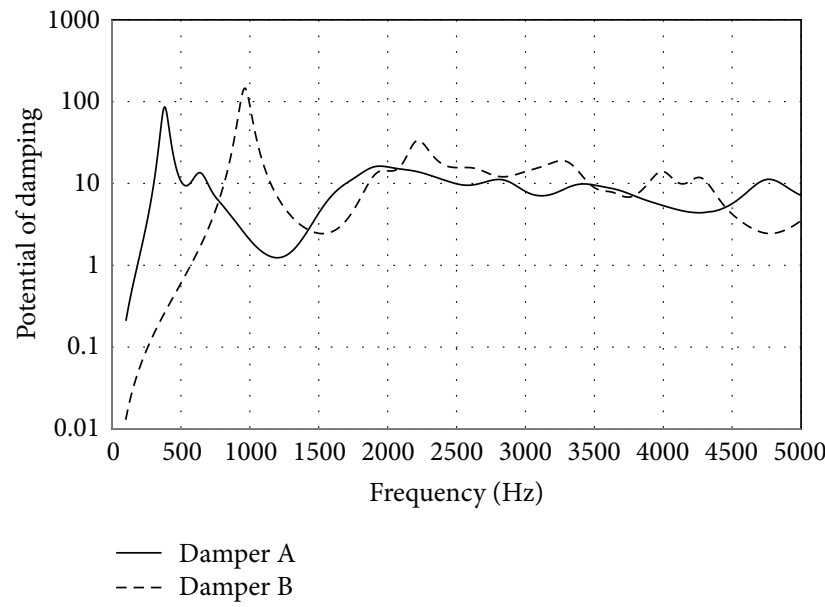

FIGURE 13: Damping potential of two dampers designed for broadband noise.

$A$ has a valley. In this way, damper $B$ would counteract the valley effect of damper $A$ if the noise generating railway wheel mode coincided with this frequency range. These two sandwich-type CLDs can be attached to any type of railway wheel that has its first natural frequency above $380 \mathrm{~Hz}$, which is the first natural frequency of damper $A$ and therefore the first peak in the damping potential curve shown in Figure 13. In addition to this, even when the railway wheel wears down, these sandwich-type CLDs would significantly increase the wheel damping.

On the other hand, when the noise problem under study is punctual, meaning in a specific narrow frequency range, a sandwich-type CLD solution that concentrates its damping strength specifically to this frequency range is desirable. In this case, a viscoelastic material with a lower loss factor is recommended, as it would have higher peak amplitudes in the damping potential curve. However, a lower loss factor would make these peaks be more pronounced and thus the sandwich-type CLD would have to concentrate its damping strength more accurately in order to avoid the valley effect, which would be more likely to happen. In this second case, a monolayer or two-layer sandwich-type CLD approach is recommended, as it would have fewer natural modes and therefore fewer peaks in the damping potential curve, resulting in higher damping strength in the peaks that do appear. If this small number of peaks was matched to the railway wheel eigenfrequencies prone to generating noise, a significant damping increase would be achieved for these modes, resulting in a considerable reduction of the total noise level.

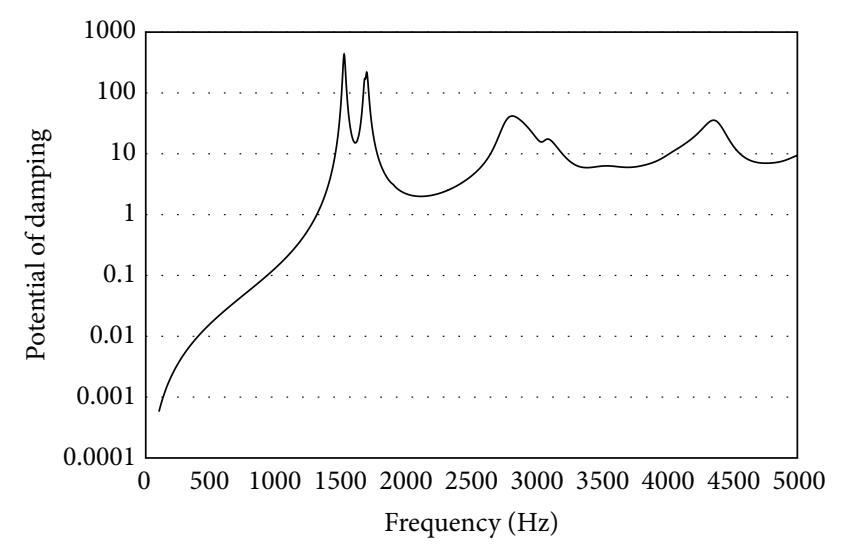

FIGURE 14: Damping potential of a damper designed for a particular purpose.

For example, Figure 14 shows the damping potential of a damper designed for a particular purpose. In comparison to the previously mentioned damper $A$ and damper $B$, this design consists of fewer peaks in the $100-5000 \mathrm{~Hz}$ frequency range, and therefore fewer modes. In this way, the total amount of damping potential is concentrated in these specific frequencies, which have to be tuned to the railway wheel modes to be damped.

In addition to this, it has been demonstrated that normally the first natural frequency of a sandwich-type CLD has the highest damping strength. If the railway wheel mode to be damped was at a high frequency, in order to match the damper's first eigenfrequency with wheel mode's frequency, a stiff viscoelastic material would be desirable, since it would locate the natural modes of the sandwich-type CLD at higher frequencies, allowing the matching of the sandwich-type CLD's first natural frequency with the natural frequency of the railway wheel that is to be damped.

\section{Conclusions}

Given that the noise generated by a railway wheel is inversely related to the damping of its modes, the higher the damping is, the lower the emitted noise will be. Among the different ways of increasing wheel damping, this paper focused on sandwich-type CLDs.

For structural or acoustic simulations of damped railway wheels, the damping added by a given sandwich-type CLD solution has to be known. According to the literature, these damping values can be theoretically predicted. They depend on both the sandwich-type CLD design and the railway 
wheel. However, a damping solution that is not effective for a given railway wheel might be very effective for another one, and the literature does not give any guidelines or recommendations for optimally evaluating sandwich-type CLD solutions without taking the railway wheel into account. This paper intends to fill this gap: it presents the influence that several sandwich-type CLD design parameters have on damping strength, which yields the most appropriate design of a sandwich-type CLD for a given railway wheel.

The concept of damping potential has been defined to represent the damping strength of a given sandwich-type CLD design. Using this concept and the procedure presented here, sandwich-type CLD designs have been simulated in order to study the influence of the properties of the viscoelastic material, the geometric parameter design of the metallic sheets, and viscoelastic layers, as well as the order in which different components of the sandwich-type CLD are assembled. It has been shown that the sandwich-type CLD solution presents wide design capabilities for increasing wheel damping under noise problems of diverse characteristics. A collection of design recommendations has been provided throughout the paper.

In sum, this procedure serves to qualitatively compare different sandwich-type CLD solutions, facilitate design stage decisions, and significantly reduce cost and time. For a given problem for a specific railway wheel, the proper geometry, material, and damping configuration can be chosen in order to achieve the most appropriate solution in an efficient way.

\section{Conflict of Interests}

The authors declare that there is no conflict of interests regarding the publication of this paper.

\section{Acknowledgment}

This work is part of the research project ecoTRANS, led by CAF, which is partially funded by the Spanish MICINN (Ministry of Science and Innovation) through the CENIT Programme.

\section{References}

[1] C. Talotte, P.-E. Gautier, D. J. Thompson, and C. Hanson, "Identification, modelling and reduction potential of railway noise sources: a critical survey," Journal of Sound and Vibration, vol. 267, no. 3, pp. 447-468, 2003.

[2] Working Group Railway Noise of the European Commission, Position Paper on the European Strategies and Priorities for Railway Noise Abatement, 2003.

[3] P. J. Remington, "Wheel/rail noise-part I: characterization of the wheel/rail dynamic system," Journal of Sound and Vibration, vol. 46, no. 3, pp. 359-379, 1976.

[4] D. Thompson and C. Jones, "Noise and vibration from railway vehicles," in Handbook of Railway Vehicle Dynamics, pp. 279325, CRC Press, London, UK, 2006.

[5] M. J. Rudd, "Wheel/rail noise-part II: wheel squeal," Journal of Sound and Vibration, vol. 46, no. 3, pp. 381-394, 1976.
[6] H. Sakamoto, "An analytical model for the natural frequencies of a railway wheel and comparison with experimental results," Proceedings of the Institution of Mechanical Engineers, Part F: Journal of Rail and Rapid Transit, vol. 221, no. 3, pp. 391-398, 2007.

[7] L. G. Kurzweil, "Wheel/rail noise-means for control," Journal of Sound and Vibration, vol. 87, no. 2, pp. 197-220, 1983.

[8] P. Bouvet, N. Vincent, A. Coblentz, and F. Demilly, "Optimization of resilient wheels for rolling noise control," Journal of Sound and Vibration, vol. 231, no. 3, pp. 765-777, 2000.

[9] C. J. C. Jones and D. J. Thompson, "Rolling noise generated by railway wheels with visco-elastic layers," Journal of Sound and Vibration, vol. 231, no. 3, pp. 779-790, 2000.

[10] H. Claus and W. Schiehlen, "Dynamic stability and random vibrations of rigid and elastic wheelsets," Nonlinear Dynamics, vol. 36, no. 2, pp. 299-311, 2004.

[11] J. F. Brunel, P. Dufrénoy, and F. Demilly, "Modelling of squeal noise attenuation of ring damped wheels," Applied Acoustics, vol. 65, no. 5, pp. 457-471, 2004.

[12] J. F. Brunel, P. Dufrénoy, M. Naït, J. L. Muñoz, and F. Demilly, "Transient models for curve squeal noise," Journal of Sound and Vibration, vol. 293, no. 3-5, pp. 758-765, 2006.

[13] F. Létourneaux, J. Cordier, F. Poisson, and N. Douarche, "High speed railway noise: assessment of mitigation measures," in Noise and Vibration Mitigation for Rail Transportation Systems, B. Schulte-Werning, D. Thompson, P.-E. Gautier et al., Eds., vol. 99 of Notes on Numerical Fluid Mechanics and Multidisciplinary Design, pp. 56-62, Springer, Berlin, Germany, 2008.

[14] J. Brunel, P. Dufrénoy, and F. Demilly, "Numerical approach for the attenuation of squeal noise of railway wheels in narrow curves," in Proceedings of the 8th International Conference on Contact Mechanics and Wear of Rail/Wheel Systems (CM '09), Firenze, Italy, 2009.

[15] Construcciones y Auxiliar de Ferrocarriles S A (CAF), “2 130 952. Sistema de amortiguamiento de ruido en ruedas ferroviarias," Patent 2130 952, Gipuzkoa, Spain, 1999.

[16] I. López Arteaga, Theoretical and experimental analysis of ringdamped railway wheels [Ph.D. thesis], Tecnun-University of Navarra, San Sebastián, Spain, 1998.

[17] E. M. Austin and D. J. Inman, "Some pitfalls of simplified modeling for viscoelastic sandwich beams," Journal of Vibration and Acoustics, vol. 122, no. 4, pp. 434-439, 2000.

[18] P. Y. H. Huang, P. G. Reinhall, I. Y. Shen, and J. M. Yellin, "Thickness deformation of constrained layer damping: an experimental and theoretical evaluation," Journal of Vibration and Acoustics, vol. 123, no. 2, pp. 213-221, 2001.

[19] M. Guerich and S. Assaf, "Optimization of noise transmission through sandwich structures," Journal of Vibration and Acoustics, vol. 135, no. 5, Article ID 051010, 13 pages, 2013.

[20] L. Zheng, Q. Qiu, H. Wan, and D. Zhang, "Damping analysis of multilayer passive constrained layer damping on cylindrical shell using transfer function method," Journal of Vibration and Acoustics, vol. 136, Article ID 031001, 2014.

[21] S. Cervello, G. Donzella, A. Pola, and M. Scepi, "Analysis and design of a low-noise railway wheel," Proceedings of the Institution of Mechanical Engineers, Part F: Journal of Rail and Rapid Transit, vol. 215, no. 3, pp. 179-192, 2001.

[22] A. Bracciali, "Damped wheels as an efficient measure to reduce railway noise," in Proceedings of the 5th European Conference on Noise Control (Euronoise 2003), Naples, Italy, May 2003. 
[23] I. López, J. M. Busturia, and H. Nijmeijer, "Energy dissipation of a friction damper," Journal of Sound and Vibration, vol. 278, no. 3, pp. 539-561, 2004.

[24] J. C. O. Nielsen and C. R. Fredö, "Multi-disciplinary optimization of railway wheels," Journal of Sound and Vibration, vol. 293, no. 3-5, pp. 510-521, 2006.

[25] A. Bracciali, S. Cervello, and P. Gatti, "Acoustic effectiveness of damped wheels and impact on life-cycle cost of different typologies of passenger trains," in Noise and Vibration Mitigation for Rail Transportation Systems, B. Schulte-Werning, D. Thompson, P.-E. Gautier et al., Eds., vol. 99 of Notes on Numerical Fluid Mechanics and Multidisciplinary Design, pp. 257-263, Springer, Berlin, Germany, 2008.

[26] J. Färm, "Evaluation of wheel dampers on an intercity train," Journal of Sound and Vibration, vol. 267, no. 3, pp. 739-747, 2003, Proceedings of the 7th International Workshop on Railway Noise.

[27] S. Cervello and F. Lombardo, "Development of a modular damping system against wheel noise emission for freight and urban transport vehicles," in Proceedings of the 56th UITP World Congress, International Association of Public Transport, Rome, Italy, June 2005.

[28] Z. Wang, Z. B. Chen, and M. Z. Li, "Added viscoelastic wheel dampers for reducing railway noise," in Proceedings of the ASME International Mechanical Engineering Congress and Exposition (IMECE '08), vol. 11, pp. 461-471, Boston, Mass, USA, November 2008.

[29] I. Merideno, J. Nieto, N. Gil-Negrete, A. Landaberea, and J. Iartza, "Constrained layer damper modelling and performance evaluation for eliminating squeal noise in trams," Shock and Vibration, vol. 2014, Article ID 473720, 11 pages, 2014.

[30] I. Merideno, J. Nieto, N. Gil-Negrete, J. G. G. Ortiz, A. Landaberea, and J. Iartza, "Theoretical prediction of the damping of a railway wheel with sandwich-type dampers," Journal of Sound and Vibration, vol. 333, no. 20, pp. 4897-4911, 2014.

[31] I. Merideno, J. Nieto, N. Gil-Negrete, J. G. Gimenez, A. Landaberea, and J. Iartza, "Numerical characterization of railway wheels with sandwich-type damping solutions," in Proceedings of the International Conference on Noise and Vibration Engineering (ISMA '14), P. Sas, D. Moens, and H. Denayer, Eds., KU Leuven-Departement Werktuigkunde, Leuven, Belgium, September 2014.

[32] D. J. Thompson and C. J. C. Jones, "Review of the modelling of wheel/rail noise generation," Journal of Sound and Vibration, vol. 231, no. 3, pp. 519-536, 2000.

[33] I. Merideno, J. Nieto, N. Gil-Negrete, A. Landaberea, and J. Iartza, "Numerical vibro-acoustic analysis of railway wheels with and without damping solutions," Noise Control Engineering Journal, vol. 60, no. 4, pp. 458-472, 2012.

[34] P. B. Lindley, Engineering Design with Natural Rubber, Natural Rubber Producers' Research Association, London, UK, 1970.

[35] A. D. Nashif, D. I. G. Jones, and J. P. Henderson, Vibration Damping, John Wiley \& Sons, New York, NY, USA, 1985.

[36] D. I. G. Jones, Handbook of Viscoelastic Vibration Damping, John Wiley \& Sons, New York, NY, USA, 2001. 


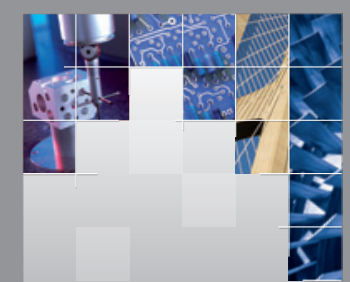

\section{Enfincering}
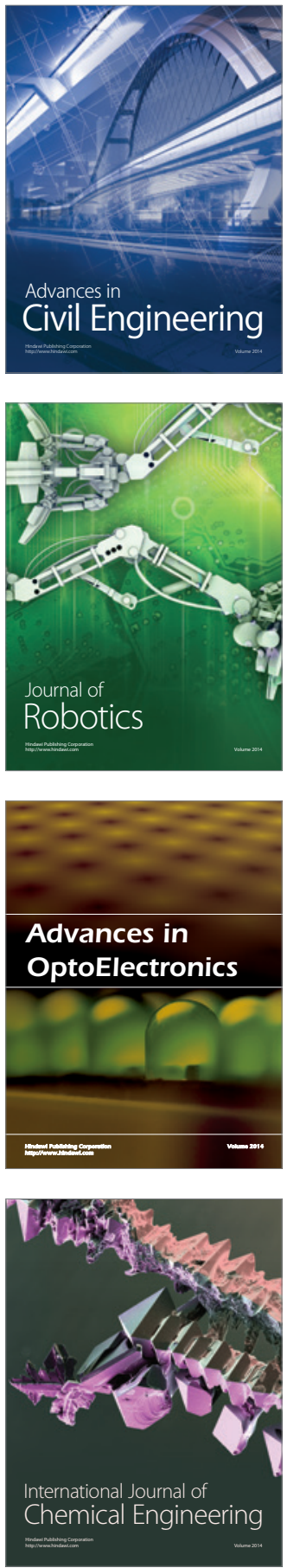

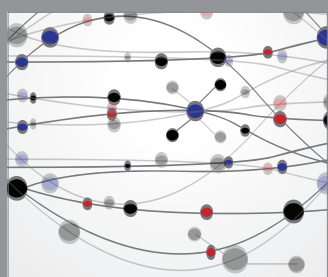

The Scientific World Journal

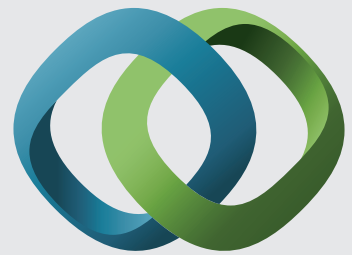

\section{Hindawi}

Submit your manuscripts at

http://www.hindawi.com
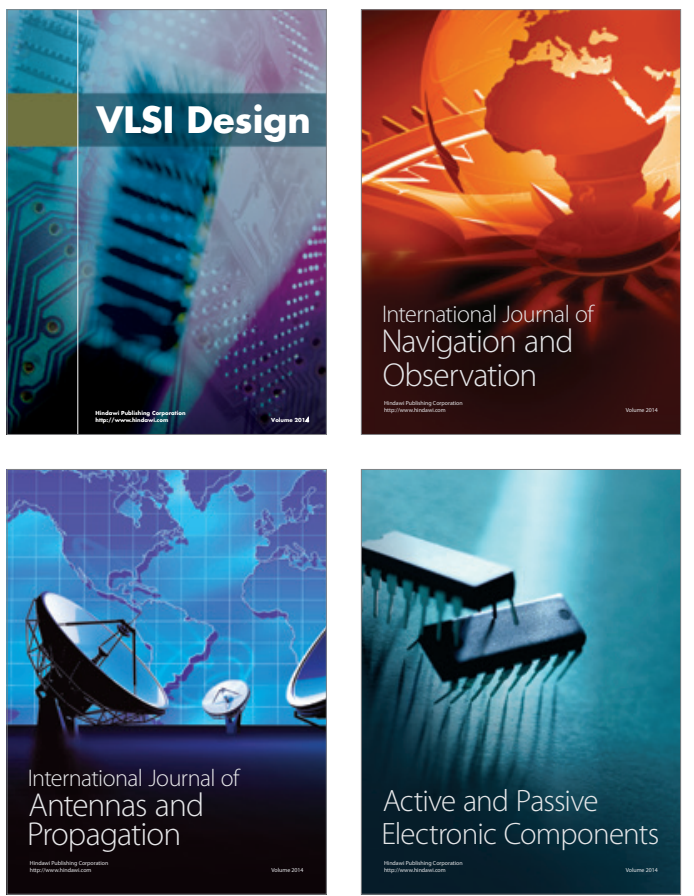
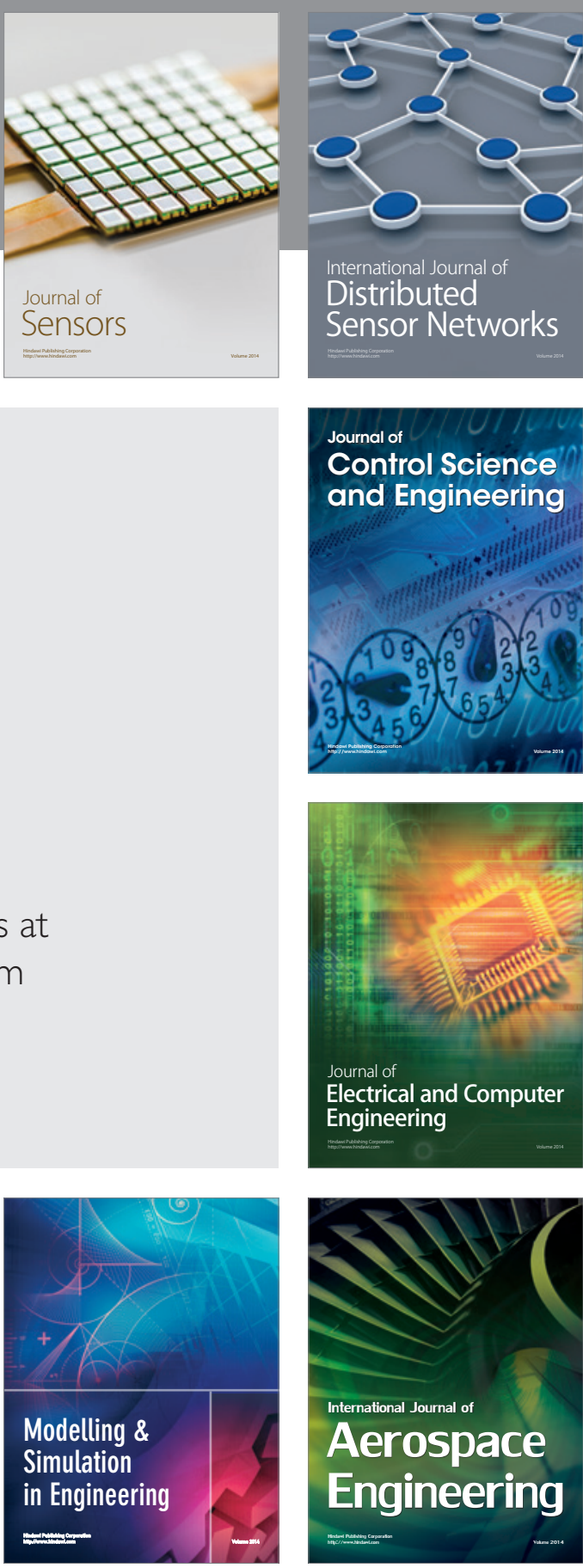

International Journal of

Distributed

Sensor Networks

Journal of

Control Science

and Engineering
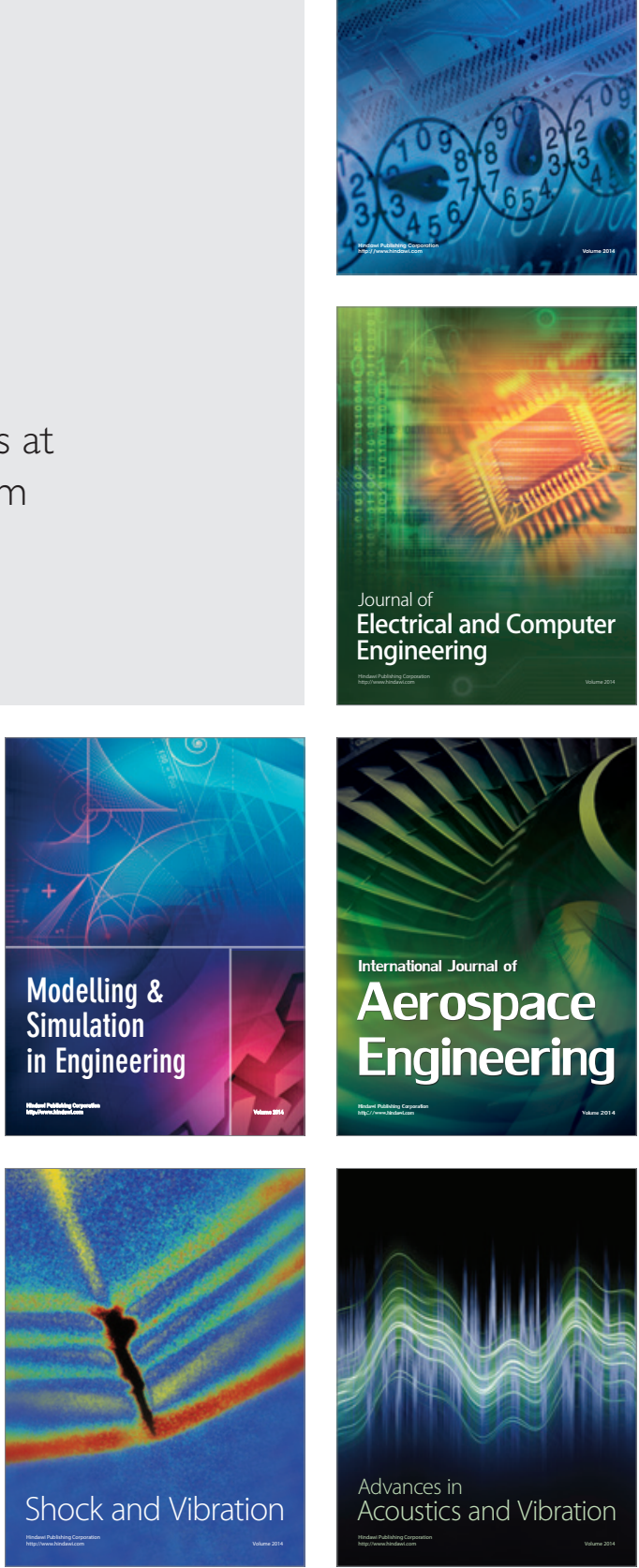